\title{
SPECTRAL CHARACTERISTIZATION OF RICE FIELD USING MULTI- TEMPORAL LANDSAT ETM+ DATA
}

\section{NUARSA I WAYAN ${ }^{1}$, SUSUMU KANNO $^{2}$, YASUHIRO SUGIMORI ${ }^{2}$, FUMIHIKO NISHIO $^{3}$}

\section{Abstract}

The preliminary study using Landsat ETM+ to estimate the rice production in Regency of Tabanan, Bali Province was conducted. The objectives of this study were to know spectral characteristic of rice plant in three importance growth periods of rice, and to develop a model to identify the distribution of rice. Landsat ETM+ in two acquisition dates (March 21 ${ }^{\text {st }}, 2003$ and May 24*, 2003) were used in this study. Characteristics of rice were analyzed using radiance value of Landsat ETM+ obtained from converting digital number of Landsat data. Multi-variable linear regression analysis was developed to classify the rice in its growth period. The result showed that the rice plant has different reflectance in seedling-development period, ear differentiation period and maturation period. It is expressed by the radiance value of Landsat ETM+. However, spectral characteristic of rice in each band of Landsat ETM+ is similar to the green vegetations in general, except in blue band (B1). Based on statistical analysis, the classification of rice in each its growth period can be classified.

Key words: Rice field, Landsat ETM+, Spectral Characteristic, Multi-temporal.

\section{Introduction}

Rice plant (Oryza sativa L.) is one of the most important agriculture plants in Indonesia because rice is the main food for Indonesian people. Until now, Indonesia still been importing rice from other countries, such as Thailand, Philippines, and Vietnam, because total production of rice is lower than required. In 2004 Indonesian government imported around 200,000 tons of rice (Bali Post, 2004).

In order to know the amount and time of rice to be imported, the requirement and production of rice should be estimated. Utilization of remote sensing data to monitor and estimate a production of rice at recent time is increasing, because this method can speed up monitoring and prediction of time, and reduces the study cost (Haggett, 1972; Paine, 1981). The result of previous research showed that using satellite digital image to monitor rice growth gives satisfaction results (David et al, 2003; Panigrahy and Sharma, 1997), as shown from the accuracy level of obtained image classification. Oette et al (2000) make a $26 \%$ errors using Landsat TM, and Shao et al (2001) using RADARS AT satellite image gets $91 \%$ accuracy.

Most of the previous studies of rice monitoring used active microwave (RADAR) data and restricted on classification of rice using the existing method (Shao et al, 1997; Kuroso et al, 1997; Le Toan et al, 1997). Only a few papers specifically focussed on rice monitoring and estimation of production using an optical remote sensing. This study is the preliminary of using Landsat ETM+ 
to predict the rice production.

The objectives of this study are:

1. To know spectral characteristic of the rice plant in three importance growth period of rice: at the end of the seedlingdevelopment period, in the ear differentiation period, and at the beginning of the harvest period.

2. To develop a model to identify the distribution of the rice in its growth period.

\section{Methodology}

\subsection{Test site and sample description}

This study was carried out in Tabanan Regency, Province of Bali, Indonesia, centered at $8^{\circ} 29^{\prime} 46^{\prime \prime} \mathrm{S}$ and $115^{\circ} 29^{\prime} 48^{\prime \prime} \mathrm{E}$ (Figure 1). Subak, the farmer organization that manages the irrigation water was used as sample site. Each Subak usually plants rice in the same time. Subak Lanyah Delod Jalan and Subak Kelepug were selected to compare the process of rice growth in this research, and the total area of plantation is $240 \mathrm{Ha}$ and $165 \mathrm{Ha}$, respectively. The rice in Subak Lanyah Delod Jalan was planted on the third week of January 2003 and in the fourth week of February 2003 for Subak Kelepug. Both of Subak in test site used IR64 of rice variety with the life cycle around 115 days and the yield reaching is 5.0 tons/Ha.

There are five major growth periods in the life cycle of rice: (1) Transplanting period when rice seedlings are transplanted from the seedbed to the paddy field; (2) Seedling development period when the seedling begins to develop a root system and start tillering during the vegetative growth stage; (3) Ear differentiation period when end of vegetative growth to start reproductive stage; (4) Heading period when rice head begin to form during the reproductive stage; (5) Maturation period when the rice plants mature and are ready to harvest. In the life cycle of rice, actually there are three stages of the growth periods that have a significant difference of reflectance in a remote sensing data (Shao et al, 2001). Therefore, this study focuses on three growth periods; those are seedling-development period, ear differentiation period, and maturation period.

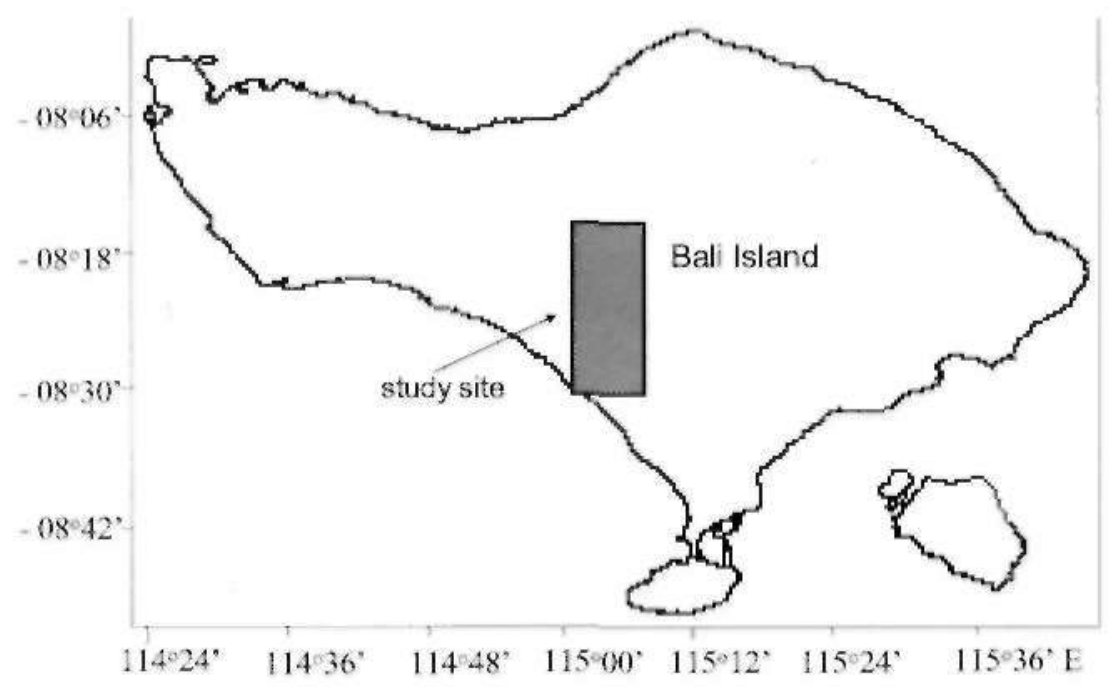

Figure 1. Map of the study sites 


\subsection{Data and used software}

A Landsat Enhanced Thematic Mapper plus (ETM+) path 116, row 66 was used in this study. The acquisition dates of the Landsat were on March $21^{\text {st }}, 2003$ and May $24^{\text {th }}, 2003$. The Band of the Landsat ETM+ selected in this study is depicted in Table 1.

Table 1. Description of the Landsat Band used in the study.

\begin{tabular}{|c|c|c|}
\hline Band & Band Width & $\begin{array}{c}\text { Ground } \\
\text { Resolution }(\mathrm{m})\end{array}$ \\
\hline 1 & $\begin{array}{c}0.45-0.52 \text { um } \\
(\text { Blue })\end{array}$ & 30 \\
\hline 2 & $\begin{array}{c}0.52-0.60 \text { um } \\
\text { (Green) }\end{array}$ & 30 \\
\hline 3 & $\begin{array}{c}0.63-0.69 \text { um } \\
(\text { Red })\end{array}$ & 30 um \\
\hline 4 & $\begin{array}{c}0.75-0.90 \text { um } \\
\text { (Near IR) }\end{array}$ & 30 \\
\hline 5 & $\begin{array}{c}1.55-1.75 \text { urn } \\
(\text { SWIR })\end{array}$ & 30 \\
\hline 7 & $\begin{array}{c}2.08-2.35 \text { um } \\
\text { (SWIR) }\end{array}$ & 30 \\
\hline
\end{tabular}

Digital image processing and GIS process used he ILWIS (Integrated Land and Water Information System) software were used for digital image processing and GIS process. Microsoft Excel was used for data calculation, and SPSS software was selected for statistical analysis.

\subsection{Research Procedure}

First, the image by digital number was converted to radiance value to facilitate making absolute comparisons and calculations of the radiance value of the rice in different acquisition date. The calibration equation used to convert $\mathrm{DN}$ of Landsat ETM+ to radiance value is expressed in the following below:

$$
L_{\lambda}=L_{\min \lambda}+\left(\frac{L_{\max \lambda}-L_{\min \lambda}}{255}\right) * D N
$$

where $L_{\lambda}, L_{\min \lambda}, L_{\max \lambda}$, and $\mathrm{DN}$ are radiance value in $\mathrm{Wm}^{-2} \mathrm{sr}^{-1}$, minimum radiance value, maximum radiance value, and digital number of the original image respectively. $L_{\min \text { A }}, L_{\max \text { A }}$ was given from image header of Landsat data.

Study of spectral signature of rice is started by collecting radiance value in three main of growth periods of the rice, i.e. seedling-development, ear differentiation, and maturation periods. Based on the radiance value in each periods, statistic value (maximum, minimum, average, and standard deviation) were calculated. Spectral signature of rice can be performed by using the average radiance value in each band of Landsat ETM+. Rice in each period can be mapped by means of multivariable linear regression analysis.

\section{Results and Discussion}

\subsection{Radiance value of rice}

According to information on the header file of Landsat ETM+, maximum and minimum radiance values in both Landsat image were used in this study (Table 2). The highest value for the maximum radiance is expressed by $\mathrm{B} 4$ and the lowest value for the minimum radiance is given by Band 2 .

The radian value of rice has a tendency to increase from first month to second month, and decrease from second month to third month for all bands, except for Band 3 (red band) (Figure 2). In seedling-development period (1 month after transplanting), coverage area of rice and water have the same portion in irrigated rice field. Band 1 of Landsat ETM+ that is definitely sensitive for the water has the highest average radiance value (52.71), and was followed by Band 2 and Band 4 that are responsive for the vegetation reflectance (41.91 and 45.53, respectively) (Table 3 ). 
Table 3. Radiance value of the rice in seedling-development period

\begin{tabular}{|l|r|r|r|r|r|r|}
\cline { 2 - 7 } \multicolumn{1}{c|}{} & \multicolumn{1}{c|}{ B1 } & \multicolumn{1}{c|}{ B2 } & \multicolumn{1}{c|}{ B3 } & \multicolumn{1}{c|}{ B4 } & \multicolumn{1}{c|}{ B5 } & \multicolumn{1}{c|}{ B7 } \\
\hline $\mathrm{n}$ & 50 & 50 & 50 & 50 & 50 & 50 \\
\hline Maximum & 55.85 & 44.52 & 32.77 & 53.79 & 7.55 & 1.36 \\
\hline Minimum & 49.65 & 38.16 & 23.48 & 35.45 & 2.39 & 0.35 \\
\hline Average & 52.71 & 41.91 & 29.08 & 45.53 & 5.52 & 0.89 \\
\hline Std. Dev. & 1.35 & 1.43 & 1.95 & 4.20 & 1.25 & 0.23 \\
\hline
\end{tabular}

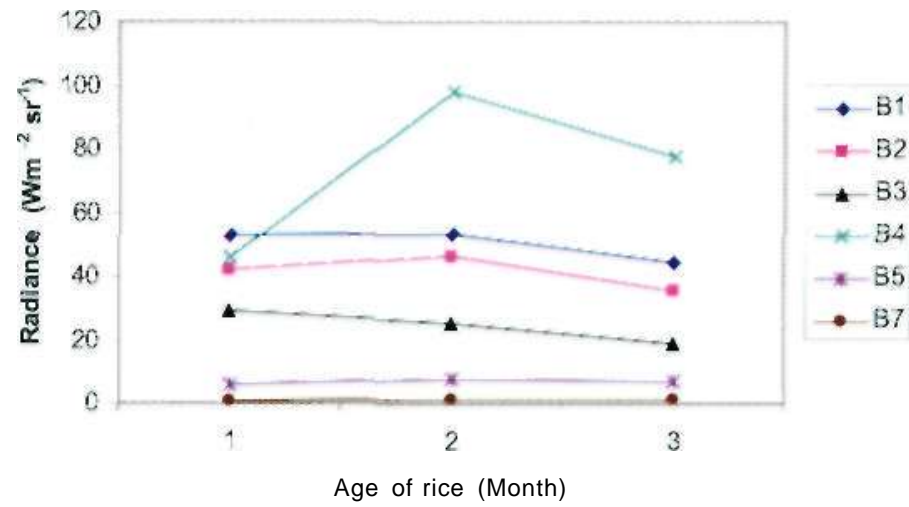

Figure 2. Average radiance value in each stage of rice

Table 3. Radiance value of the rice in seedling-development period

\begin{tabular}{|c|c|c|c|c|c|c|}
\hline & $\mathrm{Bl}$ & B2 & B3 & B4 & B5 & B7 \\
\hline $\mathrm{n}$ & 50 & 50 & 50 & 50 & 50 & 50 \\
\hline Maximum & 55.85 & 44.52 & 32.77 & 53.79 & 7.55 & 1.36 \\
\hline Minimum & 49.65 & 38.16 & 23.48 & 35.45 & 2.39 & 0.35 \\
\hline Average & 52.71 & 41.91 & 29.08 & 45.53 & 5.52 & 0.89 \\
\hline Std. Dev. & 1.35 & 1.43 & 1.95 & 4.20 & 1.25 & 0.23 \\
\hline
\end{tabular}

In ear differentiation period ( 2 months after transplanting), all of the coverage area is a rice with the maximum growth. Band 4 of Landsat ETM+ that was operated in near infrared region has the highest average value (97.74) (Table 4).

In the maturation period ( 3 months after transplanting), the rice plants are mature and ready to be harvested. In this period, greenness, chlorophyll, and water content of the rice begin to be decreasing. All of the average radiance occurs reduction, if it will be compared with previous period (Table 5).

\subsection{Spectral signature of rice}

Spectral signature of rice shows a curve, describing relationship between wave length and the radiance value of rice. The entire spectral signature curve of rice in all period shows the same pattern, similar with the spectral reflectance of the general green vegetation, except for the blue band (Lillesand and Kiefer, 1993). Reflectance of blue band in green vegetation is generally lower than blue band. However, in rice plant, blue band has Ihe higher radiance value than that of blue band with at the peak of infrared band (Figures 3,4, and 5). 
Table 5. Radiance value of the rice in the maturation period

\begin{tabular}{|l|r|r|r|r|r|r|}
\cline { 2 - 7 } \multicolumn{1}{c|}{} & B1 & B2 & B3 & B4 & B5 & H7 \\
\hline $\mathrm{n}$ & 50 & 50 & 50 & 50 & 50 & 50 \\
\hline Maximum & 47.32 & 47.71 & 23.48 & 86.62 & 8.93 & 1.22 \\
\hline Minimum & 41.12 & 30.20 & 15.43 & 64.42 & 5.54 & 0.70 \\
\hline Average & 44.27 & 35.61 & 19.12 & 77.76 & 7.23 & 1.04 \\
\hline Std. Dev. & 1.54 & 2.77 & 1.91 & 4.66 & 0.74 & 0.12 \\
\hline
\end{tabular}

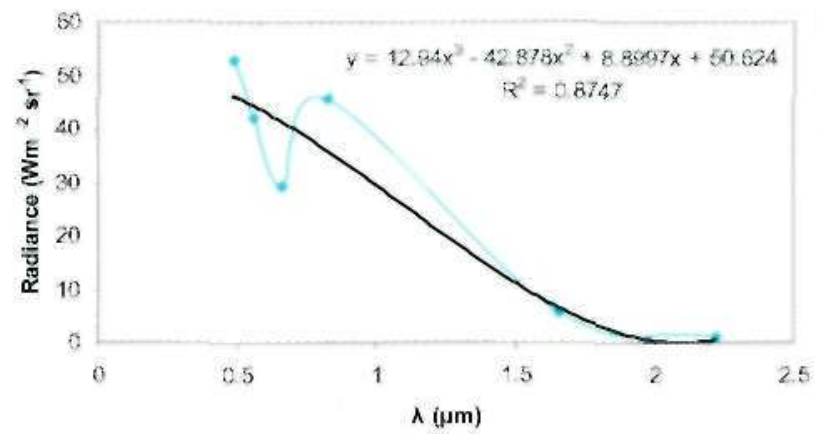

Fig. 3. Spectral signature of rice in seedling-development period.

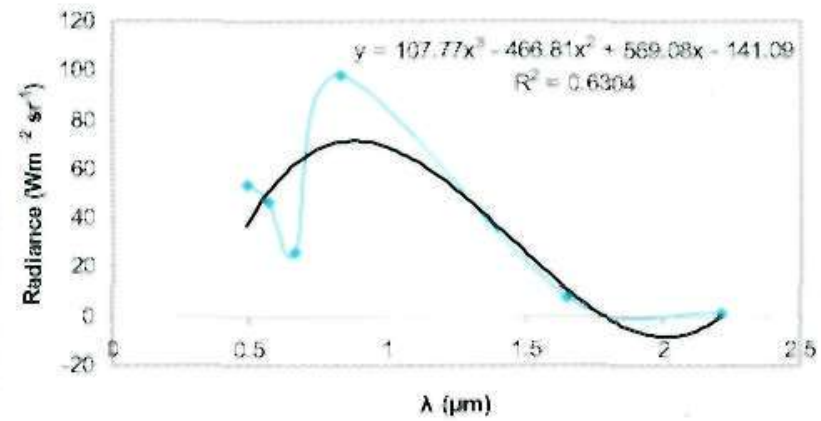

Fig. 4. Spectral signature of rice in ear differentiation period

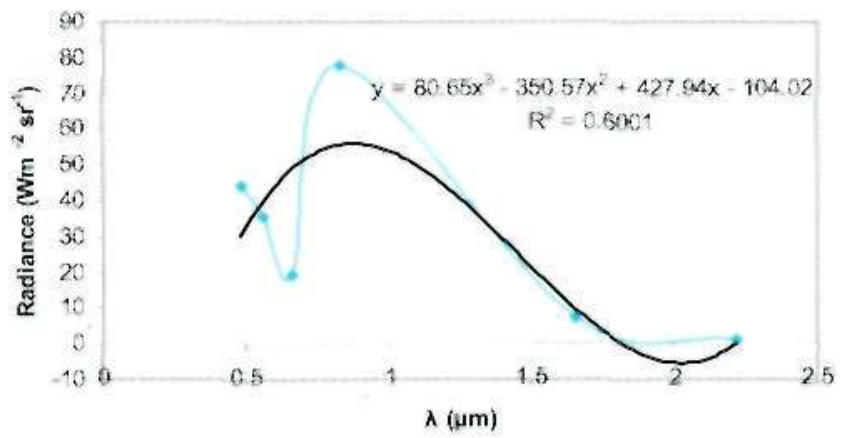

Fig. 5. Spectral signature of rice in the maturation period 
Based on the spectral signature, the model of the rice radiance was established. It is the cubic polynomial that best simulated the radiance of rice as a function of wave length for all period. In seedlingdevelopment, car differentiation and maturation periods, the cubic polynomial is expressed as;

$\mathrm{y}=12.94 \mathrm{x}^{3}-42.878 \mathrm{x}^{2}+8.8997 \mathrm{x}+50.624$ $\left(\mathrm{R}^{2}=0.8747\right)$,

$y=107.77 X^{3}-466.81 x^{2}+569.08 x-141.09$ $\left(\mathrm{R}^{2}=0.6304\right)$, and

$\mathrm{y}=80.65 \mathrm{x}^{3}-350.57 \mathrm{x}^{2}+427.94 \mathrm{x}-104.02$, $\left(\mathrm{R}^{2}=0.6001\right)$, respectively.

\subsection{Modelling of rice growth and prediction}

Based on the statistical analysis, three classification formula models have been developed. These models can be used to period. In seedling-development period, the formula model is expressed as:

$\mathrm{R} 1=-0.0213 \mathrm{~B} 1+0.02646 \mathrm{~B} 2-0.00137 \mathrm{~B} 3$

$+0.0003081 \mathrm{~B} 4)+0.158 \mathrm{~B} 5-\mathrm{B} 7+$ 0.06138 ,

where $\mathrm{R}^{2}=0.939$ and $-0.08263<\mathrm{Rl}<$ 0.08263 .

$\mathrm{R} 2=0.194 \mathrm{~B} 1-\mathrm{B} 2+0.602 \mathrm{~B} 3+0.129 \mathrm{~B} 4-$ $0.102 \mathrm{~B} 5+3.627 \mathrm{~B} 7+4.468$, where $\mathrm{R}^{2}=0.830$ and $-1.0715<\mathrm{R} 2<$ 1.0715 .

$\mathrm{R} 3=0.158 \mathrm{~B} 1+0.415 \mathrm{~B} 2-\mathrm{B} 3-0.0216 \mathrm{~B} 4$ $-0.0659 \mathrm{~B} 5-1.746 \mathrm{~B} 7+1.306$,

where $\mathrm{R}^{2}=0.620$ and $-1.5815<\mathrm{R} 3<$ 1.5815 .

These models can be applied in an original Landsat ETM+ with the radiance value. The result of classification on the third of rice period is shown in Figure 6.

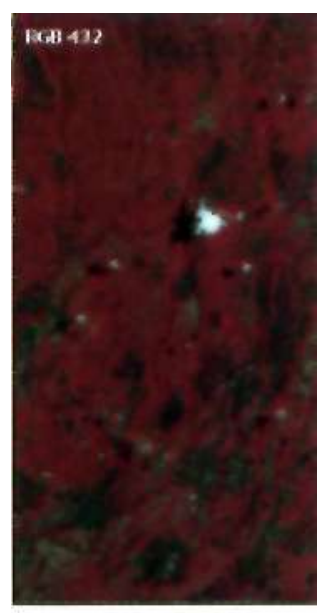

(a)

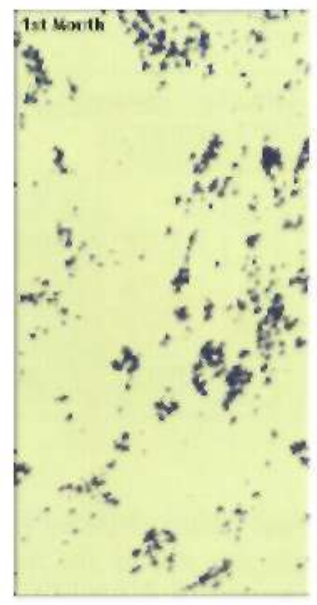

(b)

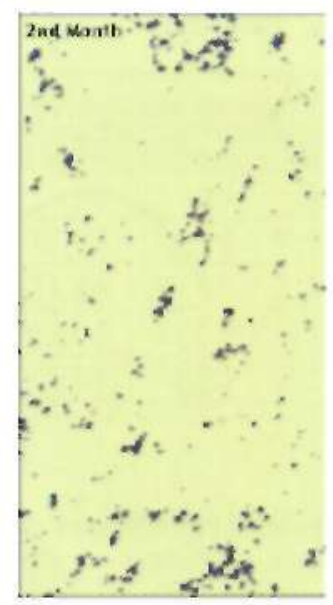

(c)

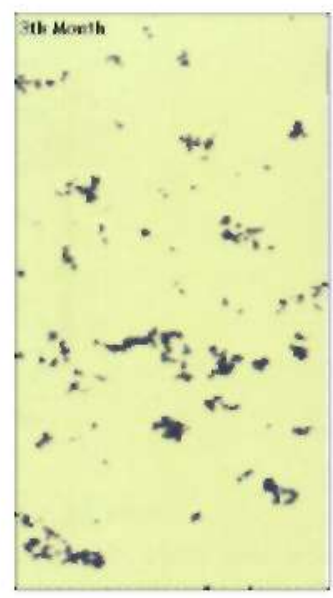

(d)

Figure 6. Using of the model to classify a rice, (a) Original Landsat ETM+, (b) rice in seedling-development period, (c) ear differentiation period, and (d) maturation period.

\section{Conclusion}

Rice plant has a different reflectance during seedling- development period, ear differentiation period and maturation period. It is illustrated by the radiance value of Landsat ETM+. However, spectral identify the rice growth in each characteristic of rice in each band of Landsat ETM+ is similar with the green vegetation in general, except in blue band (B1). Based on the multi-variable linear regression analysis, the rice in each growth period can be classified. 


\section{References}

Bali Post, 2004. Buhg Import 200.000 Tons of Rice in 2004. Bali Post Newspaper, February $11 *, 2004$, p. 2 .

Dawe, D.; S. Frolking, and C. Li, 2003. Trends in Rice-Wheat Area in China. Field Crops Research.

Hagget, P. 1973. Geography, A Modern Synthesis. Harper \& Row Publisher, New York. 225 pp.

Kuroso, T.; M. Fujita; and K. Chiba, 1997. Monitoring of Rice Fields Using MultiTemporal ERS-1 C-band SAR Data. International Journal of Remote Sensing, 18 (14), 2953-2965.

Le Toan, T.; F. Ribbes: N.L. Floury; J. Kong; T. Korosu; and M. Fujita, 1997. Rice Crop Mapping and Monitoring Using ERS-1 Data Based on Experiment and Modeling Results. IEEE Transactions on Geosciences and Remote Sensing, 35 (1), 41-56).

Lillesand, T.M. and R.W. Kiefer, 1994. Remote Sensing and Image Interpretation. Third Edition. John Wiley and Sons, New York. $750 \mathrm{pp}$.
Oette, D. R.; W. B. Cohen; B. Mercedes; T.K. Maiersperger; and R.E. Kennedy, 2000. Land Cover Mapping in Agricultural Setting Using Multiseasonal Thematic Mapper Data. Remote Sensing of Environment 76 (2000) 139-155.

Paine, D.P., 1981. Aerial Photography and Image Interpretation for Resource Management. John Wiley and Sons, New York. 412 pp.

Panigrahy, S. and S.A. Sharma, 1997. Mapping of Crop Rotation Using Multidate Indian Remote Sensing Satellite Digital Data. ISPRS Journal of Photogrammetry \& Remote Sensing 52 (1997) 85-91.

Shao Y.; X. Fan; H. Liu; J. Xiao; S. Ross; B. Brisco; R. Brown; and G. Staples, 2001. Rice Monitoring and Production Estimation Using Multitemporal RADARSAT. Journal of Remote Sensing for Environment 76: 310-325.

Shao Y.; C. Wang; X. Fan; and H. Liu, 1997. Evaluation of SAR image for Rice Monitoring and Land Cover Mapping. Presented at Geomatics in Era of RADARSAT, Ottawa, Canada. 